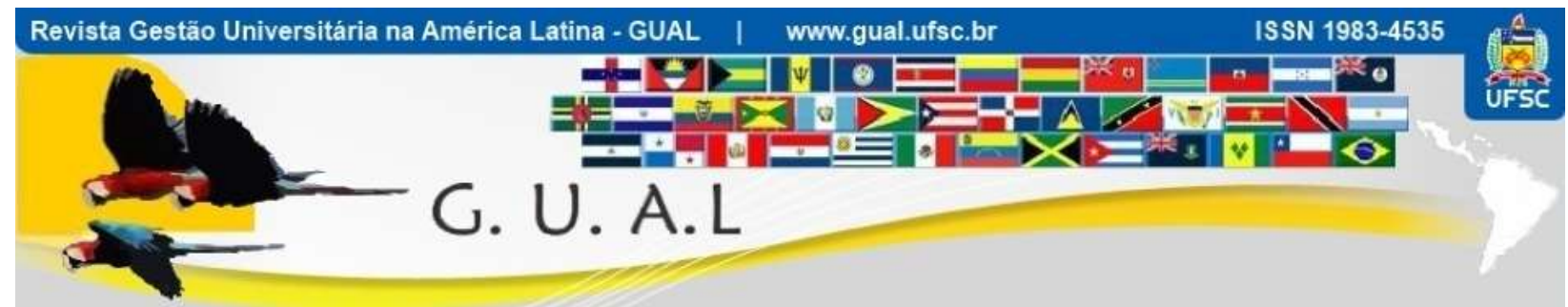

DOI: https://doi.org/10.5007/1983-4535.2021.e80590

\title{
A RELAÇÃO DOS MODELOS TEÓRICOS DA ADMINISTRAÇÃO PÚBLICA E AS COMPETÊNCIAS SOCIOEMOCIONAIS: UM ESTUDO DE CASO NO COMITÊ LOCAL DE GESTÃO DE RISCOS DO INSTITUTO FEDERAL CATARINENSE - CAMPUS CAMBORIÚ
}

\section{THE RELATIONSHIP OF THEORETICAL MODELS OF PUBLIC ADMINISTRATION AND SOCIOEMOTIONAL COMPETENCES: A CASE STUDY IN THE LOCAL MANAGEMENT COMMITTEE OF THE INSTITUTO FEDERAL CATARINENSE - CAMPUS CAMBORIÚ}

\author{
Mariana Marrara Vitarelli, Especialista \\ https://orcid.org/0000-0003-2413-7987 \\ marianamarraravitarelli@gmail.com \\ Serviço Brasileiro de Apoio às Micro e Pequenas Empresas | Unidade Santa Catarina \\ Florianópolis | Santa Catarina | Brasil \\ Loana de Moura Furlan, Especialista \\ https://orcid.org/0000-0001-8864-588X \\ loana.furlan@ifc.edu.br \\ Instituto Federal Catarinense | Campus Camboriú \\ Camboriú | Santa Catarina | Brasil \\ Diego Wander Demetrio, Mestre \\ http://orcid.org/0000-0003-1096-3903 \\ diego.demetrio@sebrae.com.br \\ Serviço Brasileiro de Apoio às Micro e Pequenas Empresas | Matriz \\ Disrito Federal | Brasília | Brasil
}

Marcos Baptista Lopez Dalmau, Doutor http://orcid.org/0000-0002-8620-1625 professordalmau@gmail.com

Universidade Federal de Santa Catarina | Programa de Pós-Graduação em Administração Universitária Florianópolis | Santa Catarina | Brasil

Recebido em 09/abril/2021

Aprovado em 05/julho/2021

Publicado em $01 /$ setembro/2021

Sistema de Avaliação: Double Blind Review
Kelly Cristina Benetti Tonani Tosta, Doutora http://orcid.org/0000-0003-0531-5282 kellycbenetti@gmail.com

Universidade Federal da Fronteira Sul | Campus Chapecó Chapecó | Santa Catarina | Brasil 


\title{
RESUMO
}

A Gestão de Riscos acontece em um contexto social, precisando ser compartilhada por pessoas que são diretamente afetadas pelo conjunto de riscos. Neste contexto, este artigo apresenta o resultado da análise da relação entre os modelos teóricos da administração pública e as competências socioemocionais requeridas dos servidores atuantes no Comitê Local de Gestão de Riscos do Instituto Federal Catarinense - Campus Camboriú. A pesquisa classificase como descritiva, do tipo estudo de caso e análise pelo método quantitativo e qualitativo. $\mathrm{O}$ estudo identifica um equilíbrio entre a Nova Administração Pública e o Novo Serviço Público. Quanto às competências, o fator Conscienciosidade e Amabilidade destacam-se como os mais relevantes para o exercício da função. Importante destacar que nos modelos teóricos da administração pública e nas competências socioemocionais não há relação de melhor ou pior classificação, sendo estes modelos abstratos e teóricos que apoiam uma observação das principais características de gestão. Contudo o estudo apresenta, em especial na concepção dos servidores, a necessidade de se capacitar e desenvolver as competências socioemocionais fundamentais ao exercício das atividades dos membros do Comitê Local da Instituição pesquisada.

Palavras-chave: Modelos Teóricos da Administração Pública. Gestão por Competências em IES. Competências Socioemocionais. Modelo dos Cinco Fatores. Gestão de Riscos.

\begin{abstract}
Risk Management takes place in a social context, needing to be shared by people who are directly affected by the set of risks. In this context, this article presents the result of the analysis of the relationship between the theoretical models of public administration and the socio-emotional competencies required of public servants on the Local Risk Management Committee of the Instituto Federal Catarinense - Campus Camboriú. The research is classified as descriptive, of the type of case study and analysis by the quantitative and qualitative method. The study identifies a balance between the New Public Administration and the New Public Service. As for skills, the Conscientiousness and Kindness factor stand out as the most relevant for the exercise of the function. It is important to highlight that in the theoretical models of public administration and in socio-emotional competences there is no relationship of better or worse classification, these being abstract and theoretical models that support an observation of the main management characteristics. However, the study shows, especially in the conception of civil servants, the need to train and develop the socio-emotional competences fundamental to the exercise of the activities of the members of the Local Committee of the researched Institution.
\end{abstract}

Keywords: Theoretical Models of Public Administration. Socioemotional Competences. Five-Factor Model. Big Five. Risk Management. 


\section{A RELAÇÃO DOS MODELOS TEÓRICOS DA ADMINISTRAÇÃO PÚBLICA E AS COMPETÊNCIAS \\ SOCIOEMOCIONAIS: UM ESTUDO DE CASO NO COMITÉ LOCAL DE GESTÃO DE RISCOS DO \\ INSTITUTO FEDERAL CATARINENSE - CAMPUS CAMBORIÚ \\ DOI: https://doi.org/10.5007/1983-4535.2021.e80590}

\section{INTRODUÇÃO}

As transformações que a sociedade do século XXI estão passando são intensas e desafiadoras, trazendo consigo desafios sociais, econômicos e educacionais em uma complexidade antes nunca vista (FADEL, BIALIK; TRILLING, 2015).

No âmbito da educação é certo que os conhecimentos cognitivos não são suficientes para uma transformação impactante na sociedade. Para tanto, é fundamental a integração dos tipos de aprendizagem. Nesse sentido, acredita-se que os entendimentos de Delors et. al. (1996) podem auxiliar, uma vez que define os quatro pilares do conhecimento a saber: aprender a conhecer, aprender a fazer, aprender a viver e aprender a ser.

Destes quatro pilares, os dois primeiros - aprender a conhecer e aprender a fazer - são os usualmente desenvolvidos formalmente através da educação formal. No entanto, dadas as complexidades do século XXI, o pilar do aprender a ser se tornou uma necessidade de extrema relevância, sendo, inclusive, atrelado a políticas públicas com o intuito de desenvolver o indivíduo de forma plena (FADEL; BIALIK; TRILLING, 2015; MARQUES; TANAKA, FÓZ, 2019).

No contexto da administração pública, a preocupação com as competências socioemocionais tornou-se ainda mais desafiadora, tendo em vista que a implementação de práticas de gestão pode variar conforme a maturidade, aspectos legais, sociais, econômicos e políticos em cada órgão ou repartição.

Historicamente a Administração Pública transitou de acordo com três tipos ou modelos teóricos: i) a Convencional ou Administração Patrimonialista - a velha gestão pública; ii) a Nova Gestão Pública - a Administração Pública Burocrática e Gerencial; iii) e o modelo emergente, conhecido como o Novo Serviço Público. Estes modelos teóricos consistem em abstrações que tentam capturar características da realidade ou propor novas visões de funcionamento de um dado sistema (DENHARDT; DENHARDT, 2000; SECCHI, 2009; PAES DE PAULA, 2005).

Contudo, Coutinho (2000) ressalta que a Administração Pública no Brasil deve ser compreendida inicialmente a partir das suas heranças, fortemente influenciadas pela falta de uma divisão clara do poder público e da atividade privada. Estes fatos motivaram a criação de padrões culturais, gerando comportamentos nos servidores públicos orientados pelo excessivo formalismo e ritualismo das regras, privilegiando rotinas administrativas departamentalizadas 


\section{A RELAÇÃO DOS MODELOS TEÓRICOS DA ADMINISTRAÇÃO PÚBLICA E AS COMPETÊNCIAS \\ SOCIOEMOCIONAIS: UM ESTUDO DE CASO NO COMITÉ LOCAL DE GESTÃO DE RISCOS DO \\ INSTITUTO FEDERAL CATARINENSE - CAMPUS CAMBORIÚ \\ DOI: https://doi.org/10.5007/1983-4535.2021.e80590}

baseadas em estruturas hierárquicas rígidas, afetando o comprometimento e a criatividade.

Atualmente, entende-se que na busca de superar o desafio de transformar estruturas burocráticas hierarquizadas em organizações flexíveis e empreendedoras, torna-se preciso adotar padrões de gestão voltados à inovação, juntamente com a introdução de uma nova cultura de gestão. Neste contexto, a Administração Pública enfrenta influências de fatores internos e externos que trazem incertezas quanto ao alcance de seus objetivos. Pode-se dizer que o efeito que essas incertezas têm sobre um evento futuro denomina-se "risco" (STEINBERG et. al., 2007).

Fundamentados nos princípios Constitucionais da Administração Pública, o Ministério do Planejamento, Desenvolvimento e Gestão e a Controladoria Geral da União (CGU) instituíram a Instrução Normativa Conjunta (INC) 01/2016, dispondo sobre controles internos, Gestão de Riscos e governança no âmbito do Poder Executivo Federal. Tal INC determinou um prazo máximo de doze meses para que os órgãos e entidades do Poder Executivo Federal compusessem a Política de Gestão de Riscos, e, na sequência, o Comitê de Governança, Riscos e Controles (BRASIL, 2016).

O Instituto Federal Catarinense (IFC), por ser uma organização pública subjugada às normas do Poder Executivo Federal, teve que adaptar suas práticas de gestão para implantar um programa de governança, riscos e controle em suas ações, adequando-se à esta determinação. Para iniciar esta atividade, foi constituído o Comitê de Governança, Riscos e Controles (CGRC), o qual elaborou um plano de ação originando a Política de Gestão de Riscos, implantada em 2018.

Na sequência, houve a criação dos comitês locais em cada um dos Campus com a responsabilidade de implementar e acompanhar a Política de Gestão de Riscos, tornando estes os representantes diretos do CGRC nos mesmos.

Para a implementação dessa estrutura, partindo das características inerentes aos modelos de Administração Pública existentes, acredita-se como pertinente conhecer as características de competências socioemocionais que os integrantes do comitê deveriam apresentar para o exercício de suas atividades. Assim sendo, este estudo tem como problema de pesquisa: considerando os modelos de Administração Pública existentes, quais as competências socioemocionais são requeridas para os servidores atuantes no Comitê Local de Gestão de Riscos do IFC - Campus Camboriú?

No que tange ao objetivo geral, este artigo visa analisar quais competências 


\section{A RELAÇÃO DOS MODELOS TEÓRICOS DA ADMINISTRAÇÃO PÚBLICA E AS COMPETÊNCIAS \\ SOCIOEMOCIONAIS: UM ESTUDO DE CASO NO COMITEE LOCAL DE GESTÃO DE RISCOS DO \\ INSTITUTO FEDERAL CATARINENSE - CAMPUS CAMBORIÚ \\ DOI: https://doi.org/10.5007/1983-4535.2021.e80590}

socioemocionais são necessárias para os servirores do IFC - Campus Camboriú, tendo como base os modelos de Administração Pública existentes e praticados.

Em relação aos objetivos específicos, tem-se o seguinte: a) identificar a relação entre o modelo de Administração Pública e as competências socioemocionais identificadas pelos membros do Comitê Local de Gestão de Riscos no IFC - Campus Camboriú; b) apresentar, na percepção dos servidores, quais as competências socioemocionais são consideradas necessárias para o desempenho das atividades do Comitê Local.

\section{MODELOS DE ADMINISTRAÇÃO.}

O Patrimonialismo é uma herança da época feudal, vigente nas sociedades prédemocráticas. De acordo com esse modelo, a Administração Pública deve atender aos interesses do governante, que faz uso do poder que emana do povo em seu favor. Assim, o Estado é uma espécie de extensão do poder do soberano (OLIVEIRA, 2010).

Para Denhardt e Denhardt (2000) são características da predominância da administração patrimonialista na gestão quando o principal fundamento metodológico é o da teoria política com comentário político aumentado pela ciência social, de forma a trazer a racionalidade sinóptica, limita e que Guerreiro Ramos irá evidenciar como o homem administrativo (RAMOS, 1989). Ainda o autor destaca que, nessa perspectiva a gestão responde ao eleitor; o seu cliente; e sintetiza que o papel do governo é de remar, de forma que é ele quem designa e implementa políticas que focalizam em um único objetivo politicamente definido. Por isso, pela figura central do monarca, o papel dos administradores na prestação de contas é bastante hierárquico, sendo que se respondem apenas ao governante (DENHARDT; DENHARDT, 2000).

A Administração Burocrática surge de forma a combater a corrupção e o nepotismo, inerentes ao modelo anterior. Dessa forma, adotam-se procedimentos legais rigorosos, estabelecendo requisitos previstos em normas, para viabilizar a prática de atos da Administração Pública.

Esta nova concepção surge então, com a contribuição da revolução industrial e o surgimento do Estado Liberal, em que houve a ascensão do capitalismo e da democracia, estabelecendo distinção entre a coisa pública e os bens privados. O modelo propõe uma desconfiança prévia dos administradores públicos por parte da sociedade, e, desta forma, a autoridade é proveniente na razão e na lei; autoridade racional-legal; para garantir a 


\section{A RELAÇÃO DOS MODELOS TEÓRICOS DA ADMINISTRAÇÃO PÚBLICA E AS COMPETÊNCIAS \\ SOCIOEMOCIONAIS: UM ESTUDO DE CASO NO COMITÉ LOCAL DE GESTÃO DE RISCOS DO \\ INSTITUTO FEDERAL CATARINENSE - CAMPUS CAMBORIÚ \\ DOI: https://doi.org/10.5007/1983-4535.2021.e80590}

efetividadeda contenção dos abusos (OLIVEIRA, 2010).

O modelo burocrático é atribuído a Max Weber (1991), pois foi quem analisou e sintetizou suas principais características. De acordo com o autor, seus principais eixos são a especialização, o controle, e, principalmente, o racionalismo (WEBER, 1991). Portanto, a racionalidade técnica e econômica, do Homem Econômico, que Guerreiro Ramos (1989) irá designar é predominante.

Neste modelo, percebe-se ainda em seu axioma fundamental a formalidade, a impessoalidade e o profissionalismo. Desse modo, o profissionalismo é uma característica que surge para minimizar os efeitos do nepotismo que dominavam o modelo pré-burocrático patrimonialista (SECCHI, 2009). Nesta perspectiva surge a figura do administrador público, já que as organizações devem ser geridas por profissionais, "pois administrar para o funcionário burocrata é sua profissão" (CAMPELO, 2010, p. 311).

Contudo, a questão do conceito de eficiência das burocracias leva ao ritualismo e à ineficiência, assim como a hierarquização e a centralização prejudicam a eficiência devido à tendência de distorção das informações, além de que esta centralização limita a capacidade de iniciativa dos subordinados (GOMES; OLIVEIRA, 2010).

A Administração Pública Gerencial ou Nova Administração Pública; new public management; apresenta-se como solução para os problemas da burocracia, priorizando a eficiência da administração, o aumento da qualidade dos serviços e a redução dos custos.

Devido às demandas oriundas da sociedade surge a necessidade de outra perspectiva para a Administração Pública que se denomina Administração Societal ou Novo Serviço Público. Para Andion (2012) o Novo Serviço Público permite compreender sob um novo olhar a ação pública na atualidade, com uma abordagem na qual o usuário do serviço deixa de ser apenas um cliente ou beneficiário, tornando-se um co-produtor do bem público, um cidadão.

Dessa forma, o sucesso de uma política pública não é determinado apenas pela aplicação de leis e normas ou pelo desempenho técnico, ela depende também do envolvimento dos cidadãos nas tomadas de decisão (comportamento cooperativo). Nesse sentido, o ajuste mútuo torna-se um elemento muito importante (ANDION, 2012, p. 10).

Esta perspectiva teórica defendida por Denhardt e Denhardt (2000), é que o papel do servidor público está em ajudar os cidadãos a se articularem e atenderem aos seus interesses, ao contrário de buscar controlar ou guiar a sociedade, expressando assim, valores societários. 
Assim, o autor se fundamenta em promover e reafirmar os valores de cidadania, democracia e do interesse público, através de sete princípios para o Novo Serviço Público, não excluindo todos os pressupostos da New Public Administration, mas sim, complementando-a (DENHARDT; DENHARDT, 2000):

a) servir, ao invés de dirigir;

b) o interesse público é o objetivo, e não apenas um subproduto;

c) pensar estrategicamente, agir democraticamente por processos colaborativos;

d) servir cidadãos e não clientes;

e) prestação de contas - Accountability;

f) valoriza as pessoas e não somente a produtividade. Processos colaborativos; e

g) valorizar a cidadania e o serviço público (DENHARDT; DENHARDT, 2000).

O quadro 01 apresenta uma síntese das unidades de análise que serão utilizadas na presente pesquisa.

Quadro 01 Perspectivas da Administração Pública

\begin{tabular}{|c|c|c|c|}
\hline Unidades de Análise & Velha Adm. Pública & Nova Adm. Pública & Novo Serviço Público \\
\hline Teoria e fundamentos & Teoria Política & Teoria Econômica & Teoria Democrática \\
\hline Modelos de Homem & Homem Administrativo & Homem Econômico & Homem Parentético \\
\hline $\begin{array}{l}\text { Concepção de } \\
\text { Interesses }\end{array}$ & $\begin{array}{l}\text { Politicamente expressa } \\
\text { na lei }\end{array}$ & Interesses individuais & $\begin{array}{l}\text { Diálogo e valores } \\
\text { compartilhados }\end{array}$ \\
\hline Respostas a: & Clientes e Eleitores & Clientes e Consumidores & Cidadãos \\
\hline Papel do Governo & Remar & Dirigir & Servir \\
\hline $\begin{array}{c}\text { Mecanismos para } \\
\text { Realizar Objetivos } \\
\text { Políticos }\end{array}$ & $\begin{array}{c}\text { Administrar programas } \\
\text { com agências } \\
\text { governamentais } \\
\text { existentes }\end{array}$ & $\begin{array}{l}\text { Mecanismos e estruturas } \\
\text { de incentivo -realizar } \\
\text { objetivos com agentes } \\
\text { privados e terceiro setor }\end{array}$ & $\begin{array}{c}\text { Coalizões entre os } 3 \text { setores } \\
\text { para atender Acordos e } \\
\text { Necessidades }\end{array}$ \\
\hline Accountability & Hierárquica & Orientado pelo Mercado & Multifacetado \\
\hline $\begin{array}{c}\text { Estrutura } \\
\text { Organizacional }\end{array}$ & Autoridade Hierárquica & Descentralizada & $\begin{array}{l}\text { Estruturas em Cooperação - } \\
\text { lideranças compartilhadas. }\end{array}$ \\
\hline
\end{tabular}

Fonte: Adaptado de Denhardt e Denhardt (2000).

Uma vez apresentados os modelos da Administração Pública,faz-se necessário discorrer sobre as competências socioemocionais e o modelo dos cinco fatores, Big Five. 


\section{COMPETÊNCIAS SOCIOEMOCIONAIS E O MODELO DOS CINCO FATORES}

Ao citar Arguelles, (1999), Guimarães, (2000) apresenta a ideia de que a abordagem da competência vem sendo direcionada aos programas de educação e gestão das relações de trabalho como uma alternativa na busca de estimular as capacidades de inovação, adaptação e aprendizagem para adequação aos requisitos do desenvolvimento econômico contemporâneo.

Como conceito de competência, Guimarães (2000) compartilha o entendimento da tríade envolvendo conhecimentos, habilidades e atitudes não apenas técnicos, mas também considerando aspectos sociais e afetivos relacionados ao ambiente, incluindo a capacidade de receber informações e introduzi-las num contexto sabendo o que está fazendo e porquê.

Já as competências socioemocionais, de acordo com Bisquerra (2012), contemplam esta mesma tríade direcionada a compreender, expressar e regular de forma apropriada os fenômenos emocionais. Compreendem assim, um conjunto de termos para habilidades como a inteligência emocional, competência social e autorregulação, englobando os processos emocionais, às habilidades interpessoais e à regulação cognitiva (MARQUES; TANAKA; FÓZ, 2019).

O inter-relacionamento das habilidades sociais e emocionais apoia os indivíduos a lidar melhor com as emoções, a relacionar-se de forma positiva com os outros, a lidar com as demandas diárias da vida de uma maneira centrada, sendo competências fundamentais para o desenvolvimento e sucesso pessoal e profissional (PALOMERA; BRIONES; GÓMEZ LINARES, 2019).

São inúmeras as definições de competências socioemocionais, sendo o acrógrafo OCEAN utilizado para reverenciar as iniciais dos cinco fatores: Opennessto Experience, Conscientiouness, Extraversion, Agreeableness e Neuroticism. A tradução para o português possui algumas variações, na qual o presente artigo utilizará as definições Abertura, Conscienciosidade, Extroversão, Amabilidade e Neuroticismo.

Conforme ponderado por Dalmau (2020), existem duas classificações clássicas para as competências, podendo elas serem denominadas como competências técnicas e competências comportamentais. As técnicas contém as dimensões conhecimento e habilidades. Já as comportamentais contemplam a dimensão atitudinal que costumam ser influenciadas pelas atitudes e suas bases constituintes a saber: personalidades e valores.

$\mathrm{Na}$ visão dele, no cotidiano organizacional atual é muito comum existirem 
investimentos para o desenvolvimento das competências técnicas de um indivíduo. No entanto, é cada vez mais perceptível a preocupação com os aspectos comportamentais, uma vez que nem sempre são visíveis ou bem interpretados pelos demais integrantes das organizações, o que gera muito mais dúvidas do que certezas quanto às entregas tão requisitadas de um profissional quando se aplica o entendimento do conceito de competência.

Diante disso, são inúmeros os estudos sobre o aspecto comportamental e, em especial, sobre os aspectos de personalidade. Para tanto, cita-se o modelo dos cinco fatores, conhecido como Big Five, que agrupa os domínios de personalidades e é trabalhado por meio de "construtos latentes obtidos por análise fatorial realizada sobre respostas de amplos questionários com perguntas diversificadas sobre comportamentos representativos", considerando características de personalidade que um indivíduo poderia ter (SANTOS, et. al., 2014, p.17)

De acordo com os cinco grandes fatores de traços é apresentada uma síntese da escala de traços e as características do indivíduo que apresenta um resultado alto e baixo em cada um dos cinco fatores, conforme a demonstrado a seguir:

Quadro 02 Os cinco grandes fatores de traços e escalas ilustrativas

\begin{tabular}{|c|c|c|}
\hline $\begin{array}{c}\text { Características do indivíduo que } \\
\text { apresenta um resultado alto }\end{array}$ & Escala de Traços & $\begin{array}{c}\text { Características do indivíduo que } \\
\text { apresenta um resultado baixo }\end{array}$ \\
\hline $\begin{array}{c}\text { Curioso, interesses amplos, criativo, } \\
\text { original, imaginativo, não-tradicional }\end{array}$ & ABERTURA (O) & $\begin{array}{c}\text { Convencional, sensato, interesses } \\
\text { limitados, não artístico, não analítico }\end{array}$ \\
\hline $\begin{array}{c}\text { Organizado, confiável, trabalhador, } \\
\text { disciplinado, asseado, perseverante }\end{array}$ & $\begin{array}{c}\text { CONSCIENCIOSIDADE } \\
\text { (C) }\end{array}$ & $\begin{array}{c}\text { Sem objetivos, não confiável, } \\
\text { preguiçoso, descuidado, negligente, }\end{array}$ \\
\hline $\begin{array}{c}\text { Sociável, ativo, falante, orientado para } \\
\text { as pessoas, otimista, divertido, afetuoso }\end{array}$ & EXTROVERSÃO (E) & $\begin{array}{c}\text { Reservado, contraído, } \\
\text { indiferente, orientado para tarefas, }\end{array}$ \\
\hline $\begin{array}{c}\text { Generoso, bondoso, confiante, } \\
\text { prestativo, clemente, crédulo, honesto }\end{array}$ & AMABILIDADE (A) & $\begin{array}{c}\text { Cínico, rude, desconfiado, não } \\
\text { cooperador, manipulador }\end{array}$ \\
\hline $\begin{array}{c}\text { Preocupado, nervoso, emotivo, } \\
\text { inseguro, inadequado, hipocondríaco }\end{array}$ & NEUROTICISMO (N) & $\begin{array}{c}\text { Calmo, descontraído, não emotivo, } \\
\text { forte, seguro, auto satisfeito }\end{array}$ \\
\hline
\end{tabular}

Fonte: Adaptado de Pervin e John (2004, p. 213, apud de Andrade, 2008).

Uma vez discorrido sobre as competências socioemocionais e o modelo dos cincofatores, Big Five, faz-se necessário apresentar conceitos de Gestão de Riscos na Administração Pública. 


\section{GESTÃO DE RISCOS NA ADMINISTRAÇÃO PÚBLICA - MODELO COSO ERM}

No Brasil, com base nos componentes elencados no art. 16 da INC CGU/MP $\mathrm{N}^{\circ}$ 01/2016, o modelo de Gestão de Riscos apontado para utilização nos Órgãos Federais foi o COSO ERM (COSO II), atualizado recentemente em 2017 (Committee of Sponsoring Organizations of the Treadway Commission [COSO], 2017).

Os órgãos e entidades do Poder Executivo Federal devem implementar, manter, monitorar e revisar os controles internos da gestão tendo por base a identificação, avaliação e o gerenciamento de riscos, mitigando a probabilidade de ocorrências dos riscos, ou seu impacto nos objetivos organizacionais. Contudo, a transformação de conceitos abstratos em procedimentos de aplicação prática ainda é um desafio, dificultando que os resultados almejados pela gestão sejam atingidos (BRASIL, 2016).

É de extrema importância que os colaboradores tenham a clareza de que o gerenciamento dos riscos auxilia a unidade a alcançar seus objetivos, contribuindo para uma comunicação eficaz, para o cumprimento das leis e regulamentos, como também para poder evitar danos à reputação, mitigando, assim, possíveis riscos de corrupção e desvios éticos (ENAP, 2018).

Para que isto aconteça, a Gestão de Riscos não pode ser compreendida como um departamento ou função, mas sim uma fusão de cultura, competências e práticas integradas na criação e preservação de valor (COSO, 2017).

Ao citar Fagundes (2008), Moreno et. al. (2016) demonstram que as estruturas organizacionais em IES podem ser alternadas entre mecânica e orgânica conforme a necessidade que se apresenta, hora numa estrutura mais burocrática e detalhista, hora numa estrutura mais flexível, sem divisão de trabalho. A Gestão de Riscos também compartilha desta estrutura contingencial, conforme quadro a seguir:

Quadro 03 Estrutura Contingencial da Gestão de Riscos

\begin{tabular}{|l|c|c|}
\hline \multicolumn{1}{|c|}{$\begin{array}{c}\text { Desenvolvimento da } \\
\text { Gestão de Riscos }\end{array}$} & $\begin{array}{c}\text { Predominante para } \\
\text { Implantação }\end{array}$ & $\begin{array}{c}\text { Predominante para } \\
\text { Implementação }\end{array}$ \\
\cline { 1 - 1 } Divisão do Trabalho & \multicolumn{1}{|c|}{ Mecânica } & \multirow{2}{*}{ Orgânica } \\
\cline { 1 - 1 } Especialização do Trabalho & & \\
\cline { 1 - 1 } Centralização e processo decisório & & \\
\cline { 1 - 1 } Padronização das Atividades & Orgânica & \\
\cline { 1 - 1 } Ambiente Organizacional & &
\end{tabular}

Fonte: Elaborado pelos autores. 
Pensar na organização como um conjunto de relações mecânicas é esperar que sua rotina se desenvolva de maneira eficiente, confiável e previsível, geralmente identificada como organizações burocráticas num estado de relações ordenadas entre partes claramente definidas (MORGAN, 2006).

Morgan (2006) complementa ainda que as organizações que têm sucesso com o modelo mecanicista são dotadas de algumas condições como: i) tarefa clara a ser desempenhada; ii) ambiente estável e previsível; e iii) produzir sempre o mesmo produto. Estas organizações são planejadas para atingir metas e não para fazer inovações, bloqueando assim a flexibilidade e a ação criativa. E quando ocorrem mudanças, problemas e desafios, o estilo de organização aberta e flexível, como um sistema orgânico, torna-se valioso.

Por isso, um dos objetivos da Gestão de Riscos é o de mapear as atividades na visão de quem as executa, para que se possa ter uma maior interação com o grupo (FURLAN; PACHECO, 2020). Para tanto, todos os envolvidos "devem possuir as habilidades e competências necessárias para gerenciar esses riscos" (ÁVILA, 2016, p. 8).

Nesta linha, a Escola Nacional de Administração Pública (ENAP), na visão de Hill (2006, p.45), corrobora que:

\begin{abstract}
A implementação de um sistema de gestão de riscos exige um conjunto de responsabilidades e mecanismos de accountability para que um programa possa ser determinado e designado. A estrutura organizacional e o sistema de incentivos devem estar alinhados com as metas e os objetivos do programa de gestão de riscos. Os responsáveis pela implementação do programa devem ter as capacidades necessárias para essa tarefa, e cursos de capacitação e educação formal podem ser necessários para promover 0 desenvolvimento de competências específicas.
\end{abstract}

Deste modo, independente da atividade desenvolvida, a prestação do serviço público deve ser norteada pela qualidade, eficiência e efetividade. E para atingir este pressuposto, Guimarães (2000, p.130) orienta a necessidade de as organizações passarem por um processo de racionalização organizacional, adotando novos processos de gestão, organização e divisão de trabalho, superando o modelo hierárquico por um "modelo fundamentado na flexibilidade, da qual a abordagem da competência é um dos componentes".

E sendo a Gestão de Riscos corporativos mais do que um inventário de riscos ou um controle interno, seus princípios devem ser aplicados a todos os níveis da organização e todas as funções (COSO, 2017). 


\section{METODOLOGIA}

Esta pesquisa pode ser classificada como um estudo descritivo, do tipo estudo de caso, pois descreveu com exatidão os fatos e fenômenos de determinada realidade (TRIVIÑOS, 2006). Utilizou-se o método misto, sendo o quantitativo na etapa da análise das informações coletadas via questionário semi-estruturado e quanto ao conteúdo sobre a identificação das características socioemocionais investigadas. Já o método qualitativo fez-se presente na análise subjetiva das respostas quanto à percepção dos membros do Comitê sobre a estruturação da Gestão de Riscos e sua relação com o objeto do estudo (RICHARDSON, 1999).

Os participantes deste estudo foram os membros do Comitê Local do Campus Camboriú - IFC no ano de 2020. Definiu-se por estabelece-los como sujeitos da pesquisa por estes estarem entre as duas fases da Gestão de Risco na instituição - implantação e implementação, tendo, assim, uma visão mais completa do todo ao se considerar as facilidades e dificuldades do que foi realizado.

Para conhecer a percepção dos servidores quanto às competências socioemocionais requeridas utilizou-se o Big Five Inventory (Inventário dos cinco grandes fatores de personalidade - IGFP-5), composto por 44 itens: Abertura, Conscienciosidade, Extroversão, Amabilidade e Neuroticismo, conforme já apresentado na Fundamentação Teórica.

O inventário foi formatado com frases simples e respondidas em uma escala de respostas Likert de cinco pontos, sendo 1 para "discordo totalmente" e 5 para "concordo totalmente". Para os casos em que a metodologia de referência descrevia os itens de maneira em que a polaridade de resposta era em sentido inverso, houve a devida alteração dos mesmos de maneira a poder generalizar, uniformizar e ter um posicionamento mais compatível a realidade estudada.

Posteriormente às análises individuais, realizou-se uma análise cruzada entre o modelo teórico da Administração Pública com a abordagem majoritária, bem como a identificação do fator preponderante das competências socioemocionais de acordo com o modelo dos cinco fatores. Por outro lado, identificou-se as abordagens em comum de cada um dos modelos, correlacionando-as com a estrutura predominante para implantação da Gestão de Riscos, conforme quadro a seguir: 


\section{A RELAÇÃO DOS MODELOS TEÓRICOS DA ADMINISTRAÇÃO PÚBLICA E AS COMPETÊNCIAS \\ SOCIOEMOCIONAIS: UM ESTUDO DE CASO NO COMITÉ LOCAL DE GESTÃO DE RISCOS DO \\ INSTITUTO FEDERAL CATARINENSE - CAMPUS CAMBORIÚ \\ DOI: https://doi.org/10.5007/1983-4535.2021.e80590}

Quadro 04 Composição da Pesquisa

\begin{tabular}{|lcc|}
\hline \multicolumn{1}{|c}{ Objetivos Específicos } & Sujeitos & Coleta de Dados \\
\hline $\begin{array}{l}\text { 1 - Identificar a percepção dos membros do Comitê Local } \\
\text { quanto ao modelo predominante de Administração Pública } \\
\text { praticada. }\end{array}$ & $\begin{array}{c}10 \text { membros do } \\
\text { Comitê }\end{array}$ & 3 questões abertas \\
\hline $\begin{array}{l}\text { 2 - Avaliar a percepção quanto às competências } \\
\text { socioemocionais requeridas para o exercício das atividades. }\end{array}$ & $\begin{array}{c}10 \text { membros do } \\
\text { Comitê }\end{array}$ & $\begin{array}{c}44 \text { questões de escala } \\
\text { Likert de 5 pontos }\end{array}$ \\
\hline $\begin{array}{l}\text { 3 - Analisar a relação entre o modelo de Administração } \\
\text { Pública e as competências socioemocionais necessárias às } \\
\text { atividades do Comitê Local. }\end{array}$ & $\begin{array}{c}\text { IFC - } \\
\text { Administração } \\
\text { Pública }\end{array}$ & $\begin{array}{c}\text { Questionário e o } \\
\text { Referencial Teórico. }\end{array}$ \\
\hline
\end{tabular}

Fonte: Elaborada pelos autores.

A pesquisa foi encaminhada por meio de e-mail institucional com questionário autopreenchível aos dez membros do Comitê Local, sendo registradas respostas de nove integrantes. Além do questionário, utilizou-se ainda a técnica de análise documental a partir dos normativos internos e arcabouço legal, iniciando a análise conforme descrito a seguir.

\section{APRESENTAÇÃO DOS RESULTADOS}

O Comitê para Implantação da Política de Gestão de Riscos foi instituído pela Portaria 1.395/2017 (alterada pela Portaria 321/2018). Esta política instituiu que os Campi constituíssem um Comitê Local Próprio com a finalidade subsidiar sua presença e implementar os procedimentos de gerenciamento de riscos nas unidades segundo a Política de Gestão de Riscos da Instituição, privilegiando uma visão antecipada da administração (IFC, 2020).

Em face desta realidade e corroborando com a ideia Picchiai (2010) - de que o processo de formação profissional e desenvolvimento de competências são processos de aprendizagem contínuos e transitórios - observou-se a necessidade de identificar quais competências - além das técnicas - seriam necessárias para que os membros do Comitê Local de Gestão de Riscos conseguissem desenvolver as atividades e alcançarem os resultados almejados.

Assim, analisa-se na sequência a prática adotada conforme os modelos teóricos da Administração Pública e em seguida a percepção dos membros do comitê quanto às competências socioemocionais requeridas.

\subsection{MODELO DE ADMINISTRAÇÃO PÚBLICA PRATICADA}

Na percepção dos membros do Comitê Local, os objetivos de se existir a Gestão de 


\section{A RELAÇÃO DOS MODELOS TEÓRICOS DA ADMINISTRAÇÃO PÚBLICA E AS COMPETÊNCIAS \\ SOCIOEMOCIONAIS: UM ESTUDO DE CASO NO COMITÉ LOCAL DE GESTÃO DE RISCOS DO \\ INSTITUTO FEDERAL CATARINENSE - CAMPUS CAMBORIÚ \\ DOI: https://doi.org/10.5007/1983-4535.2021.e80590}

Riscos consistem em atitudes de reflexão sobre possíveis problemas ou situações indesejadas com a finalidade de prevenir e evitar danos aos servidores e à gestão, identificando os limites da Instituição e fortalecendo, assim, a segurança quanto à tomada de decisão. Isso fica cristalino ao se analisar o quadro a seguir:

Quadro 05 Objetivos da Gestão de Riscos no IFC

\begin{tabular}{|cl|}
\hline Sujeitos & Quais os objetivos de existir a Gestão de Riscos no IFC? \\
\hline S1 & Acompanhar, controlar e prevenir os riscos. \\
\hline S2 & Identificar e Monitorar riscos. \\
\hline S3 & Visão antecipada; Conhecer as limitações da Instituição. \\
\hline S4 & Pensar na prevenção para minimizar os riscos. \\
\hline S5 & Evitar acontecer situações indesejadas. \\
\hline S6 & Mais segurança ao gestor e à Instituição. \\
\hline S7 & Identificar situações e problemas para o servidor e gestão. \\
\hline S8 & Direcionar a tomada de decisão e identificar alternativas. \\
\hline S9 & Prever possíveis danos e prever soluções. \\
\hline
\end{tabular}

Fonte: Elaborada pelos autores.

Quanto à percepção do conjunto de atividades que o Comitê Local precisa desempenhar, os sujeitos identificaram o que segue:

Figura 01 Conjunto de atividades vinculadas ao Comitê Local

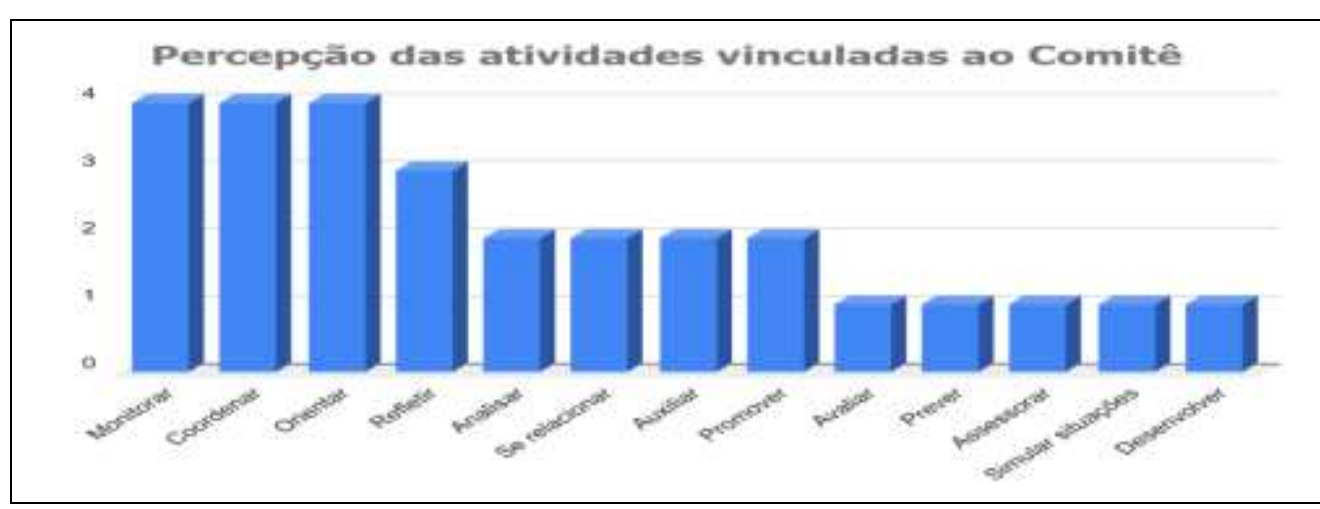

Fonte: Elaborado pelos Autores.

É possível verificar o consenso das atividades relacionadas ao envolvimento e interação com todos os setores do IFC, seja por meio da Orientação, Coordenação e Monitoramento, ou pela necessidade de relacionamento e assessoramento. Outra constatação interessante foi a necessidade de realizar atividades relacionadas à reflexão, análise, previsão e simulação de situações.

Nesta etapa da pesquisa foi possível identificar a presença do fundamento epistemológico da Teoria Econômica em virtude da sua relação com a racionalidade técnica e 


\section{A RELAÇÃO DOS MODELOS TEÓRICOS DA ADMINISTRAÇÃO PÚBLICA E AS COMPETÊNCIAS \\ SOCIOEMOCIONAIS: UM ESTUDO DE CASO NO COMITÉ LOCAL DE GESTÃO DE RISCOS DO \\ INSTITUTO FEDERAL CATARINENSE - CAMPUS CAMBORIÚ \\ DOI: https://doi.org/10.5007/1983-4535.2021.e80590}

econômica, pela formalidade na imposição de deveres e responsabilidades aos membros da instituição como um todo. Entretanto, para que a atividade se ultrapasse a fase de implantação é primordial o envolvimento dos servidores com a colaboração e inclusão de conhecimentos interpretativos e reflexivos originários da sua experiência e vivência no ambiente de trabalho.

Nota-se aqui a presença do fundamento epistemológico da Teoria Democrática, na qual os gestores contribuem para a construção do coletivo num amplo sistema de governança, pensando estrategicamente, mas agindo democraticamente, por meio de processos colaborativos, tendo os servidores a missão não só de identificar problemas, como também de atuar na busca de soluções.

Outro fator que sustenta a classificação nesta teoria é a operacionalização dos trabalhos em processos colaborativos, com liderança compartilhada focando no sucesso de longo prazo. Neste mesmo argumento, sustenta-se a classificação quanto ao modelo de homem como Homem Econômico e Homem Parentético. O primeiro justifica-se pelo cálculo utilitário de consequências oriundos da mensuração dos riscos, já o homem parentético se apresenta nas atividades de Implementação, na qual 100\% dos entrevistados consideram a necessidade de ser assertivo, insistente, criativo, inventivo e engenhoso

A etapa de levantamento dos riscos, mapeamento dos processos e registro dos respectivos controles ocorre pelo comitê em conjunto com os diversos atores relacionados à atividade ou processo em questão. Assim, é tendência a ponderação quanto a características do novo serviço público quanto ao resultado do diálogo sobre valores compartilhados.

A concepção do interesse público identifica-se nas características do novo serviço público pelo envolvimento das partes interessadas no levantamento, como servidores, gestores, membros dos Comitês Locais e do Comitê de Governança, Riscos e Controles. É unânime a visão do comitê quanto à orientação dos funcionários a responderem os clientes, isto é, nas respostas sobre para quem a Gestão de Riscos é orientada, surgiram nos contextos das respostas os alunos, a direção e os funcionários. Isto posto, corrobora o aspecto do papel do governo enquanto característica de dirigir, isto é, controlar e definir os rumos das políticas públicas.

A percepção do escopo das atividades é limitada ao contexto da própria instituição, principalmente quanto à extensão que os resultados podem propiciar, sendo a orientação um importante argumento nas respostas entrevistados. Nota-se assim uma orientação ao mercado na prestação de contas e enquanto mecanismo para a realização dos objetivos políticos, uma 
faceta bastante instrumental e orientada aos fins, isto é, objetiva e explícita. Todavia, mesmo sendo considerado pelos entrevistados como uma atividade limitada à Comunidade escolar (usuários, colaboradores e comunidade interna ao Campus), ressalta-se que os resultados da Gestão de Riscos vão além disso.

Por fim, a iniciativa de descentralizar a gestão dessa prática, concedendo certa autonomia ao Campus do Instituto Federal Catarinense e, inclusive, a um Comitê Local para o mapeamento das práticas, riscos e controles, denotam uma estrutura descentralizada. Afastamse assim conceitos de uma autoridade hierárquica suprema e unânime, direcionando a uma estrutura em Cooperação com lideranças compartilhadas no Campus e na Reitoria.

Assim, dentro da segmentação proposta por Denhardt e Denhardt (2000) da Administração Pública ser avaliada sob o ponto de vista teórico em três momentos, percebeuse a predominância dentro de cada unidade de análise proposta, conforme melhor visualizado a seguir:

Quadro 06 Avaliação das Práticas de Gestão de Riscos na percepção do Comitê Local sobre as perspectivas da Administração Pública

\begin{tabular}{|c|c|c|c|}
\hline Unidades de Análise & Velha Adm. Pública & Nova Adm. Pública & Novo Serviço Público \\
\hline $\begin{array}{c}\text { Teoria e } \\
\text { fundamentos }\end{array}$ & Teoria Política & Teoria Econômica & Teoria Democrática \\
\hline Modelos de Homem & $\begin{array}{c}\text { Homem } \\
\text { Administrativo }\end{array}$ & Homem Econômico & Homem Parentético \\
\hline $\begin{array}{l}\text { Concepção de } \\
\text { Interesse }\end{array}$ & Expressa na lei & $\begin{array}{c}\text { Agregação de interesses } \\
\text { individuais }\end{array}$ & $\begin{array}{l}\text { Diálogo e valores } \\
\text { compartilhados }\end{array}$ \\
\hline $\begin{array}{l}\text { Funcionários } \\
\text { respondem à }\end{array}$ & Clientes e Eleitores & Clientes e Consumidores & Cidadãos \\
\hline Papel do Governo & Remar & Dirigir & Servir \\
\hline $\begin{array}{c}\text { Mecanismos para } \\
\text { Realizar Objetivos } \\
\text { Políticos }\end{array}$ & $\begin{array}{l}\text { Administrar } \\
\text { programas com } \\
\text { agências } \\
\text { governamentais } \\
\text { existentes }\end{array}$ & $\begin{array}{l}\text { Mecanismos e estruturas de } \\
\text { incentivo - realizar objetivos } \\
\text { políticos com agentes } \\
\text { privados e terceiro setor }\end{array}$ & $\begin{array}{c}\text { Coalizões entre os } 3 \\
\text { setores para atender } \\
\text { Acordos e } \\
\text { Necessidades }\end{array}$ \\
\hline Accountability & Hierárquica & Orientado pelo Mercado & Multifacetado \\
\hline $\begin{array}{c}\text { Estrutura } \\
\text { Organizacional }\end{array}$ & $\begin{array}{l}\text { Autoridade } \\
\text { Hierárquica }\end{array}$ & Descentralizada & $\begin{array}{c}\text { Estruturas em Cooperação } \\
\text { com lideranças } \\
\text { compartilhadas }\end{array}$ \\
\hline
\end{tabular}

Fonte: Elaborado pelos autores. 
Mesmo com as diferenças entre cada uma das três perspectivas apresentadas, a relação entre as duas últimas são evidentes (DENHARDT; DENHARDT, 2000; SECCHI, 2009; PAES DE PAULA, 2005). Constatou-se no presente estudo um equilíbrio entre a Nova Administração Pública e o Novo Serviço Público nas atividades de Gestão de Riscos, conforme percepção dos membros do Comitê Local do IFC.

\subsection{COMPETÊNCIAS SOCIOEMOCIONAIS}

A percepção dos membros do Comitê Local de Gestão de Riscos do IFC sobre as competências requeridas, de acordo com o Big Five Inventory apresentou o fator Conscienciosidade como o mais relevante, seguido pelo fator amabilidade. Já o fator Neuroticismo apareceu como o de menor relevância.

Figura 2 Percepção do comitê interno de Gestão de Riscos sobre os cinco fatores

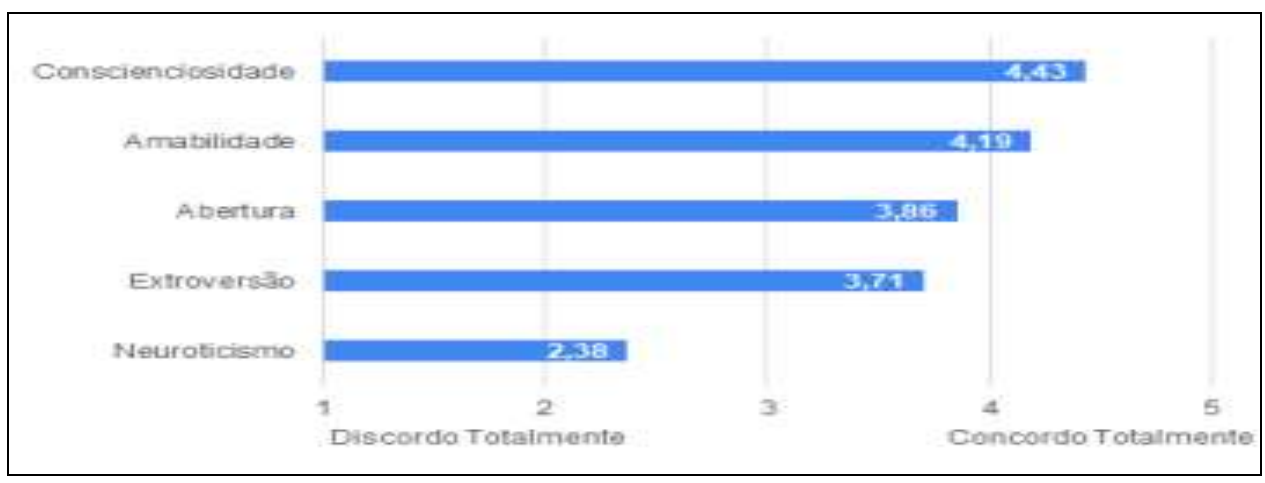

Fonte: Elaborado pelos autores.

Dentre os 44 itens avaliados 03 se destacaram como sendo mais relevantes para os membros do Comitê Local de Gestão de Riscos. São eles: ser prestativo e ajudar os outros (Amabilidade), ser geralmente confiável (Amabilidade) e ser um trabalhador de confiança (Conscienciosidade). Fica evidente a percepção dos mesmos em ser confiável, aparecendo dois itens relacionados à confiança como os mais relevantes.

O segundo grupo de itens mais relevantes foram referentes aos fatores: Abertura, comoser inventivo, criativo, curioso sobre coisas diferentes e ser engenhoso, alguém que gosta de analisar profundamente as coisas; ao fator Amabilidade com gostar de cooperar com os outros; e ao fator Conscienciosidade com os itens insistir até concluir a tarefa ou trabalho e fazer as coisas com eficiência. Destaca-se que a cooperação também apareceu no grupo de itens com maior percepção de relevância. 


\section{A RELAÇÃO DOS MODELOS TEÓRICOS DA ADMINISTRAÇÃO PÚBLICA E AS COMPETÊNCIAS SOCIOEMOCIONAIS: UM ESTUDO DE CASO NO COMITEE LOCAL DE GESTÃO DE RISCOS DO INSTITUTO FEDERAL CATARINENSE - CAMPUS CAMBORIÚ DOI: https://doi.org/10.5007/1983-4535.2021.e80590}

O terceiro grupo com maior percepção de relevância apresentou os itens ser amável e ter consideração pelos outros (Amabilidade); não ser preguiçoso (Conscienciosidade) e ser cheio de energia (Extroversão); ser assertivo e não temer expressar o que sente (Extroversão); e ser minucioso e detalhista no trabalho (Conscienciosidade).

Quadro 07 Grupos com maior percepção de relevância

\begin{tabular}{|c|c|c|c|}
\hline $\begin{array}{l}\text { Amabilidade } \\
\text { Amabilidade } \\
\text { Conscienciosidade }\end{array}$ & & $\begin{array}{l}\text { É prestativo e ajuda os outros. } \\
\text { É geralmente confiável. } \\
\text { É um trabalhador de confiança. }\end{array}$ & $\begin{array}{l}4,89 \\
4,89 \\
4,89 \\
\end{array}$ \\
\hline Abertura & & É inventivo, criativo. & 4,67 \\
\hline Abertura & & É curioso sobre muitas coisas diferentes. & 4,67 \\
\hline Abertura & & É engenhoso, alguém que gosta de analisar profundamente as coisas. & 4,67 \\
\hline Amabilidade & & Gosta de cooperar com os outros. & 4,67 \\
\hline Conscienciosidade & & Insiste até concluir a tarefa ou o trabalho. & 4,67 \\
\hline Conscienciosidade & & Faz as coisas com eficiência. & 4,67 \\
\hline Amabilidade & & É amável, tem consideração pelos outros. & 4,56 \\
\hline Conscienciosidade & Inversa & Tende a ser preguiçoso. & 4,56 \\
\hline Conscienciosidade & & É minucioso, detalhista no trabalho. & 4,56 \\
\hline Extroversão & & É assertivo, não teme expressar o que sente. & 4,56 \\
\hline Extroversão & & É cheio de energia. & 4,56 \\
\hline
\end{tabular}

Fonte: Elaborado pelos autores.

Os itens do fator Neuroticismo apareceram como os menos relevantes, sendo os itens com menor indicação de respostas: ser emocionalmente estável e se manter calmo nas situações tensas,seguidos pelos itens controlar bem o estresse, ficar nervoso facilmente e mudar de humor.

Quadro 08 Grupos com menor percepção de relevância

\begin{tabular}{|l|l|l|l|}
\hline Neuroticismo & Inversa & É emocionalmente estável, não se altera facilmente. & 1,89 \\
Neuroticismo & Inversa & Mantém-se calmo nas situações tensas. & 1,89 \\
\hline Neuroticismo & \multirow{2}{*}{$\begin{array}{l}\text { Inversa } \\
\text { Neuroticismo }\end{array}$} & $\begin{array}{l}\text { É relaxado, controla bem o estresse. } \\
\text { Fica nervoso facilmente. }\end{array}$ & 2,00 \\
\hline Neuroticismo & & É temperamental, muda de humor facilmente. & 2,22 \\
\hline Neuroticismo & & É depressivo, triste. & 2,33 \\
\hline
\end{tabular}

Fonte: Elaborado pelos autores.

Este conjunto de percepções pode ser validado junto a figura 1, sobre as atividades apontadas pelos membros do Comitê Local, na necessidade de flexibilidade e interação apresentada por Furlan e Pacheco (2020), e pelo conjunto de habilidades apontadas por Ávila (2016), como proatividade, compreensão e iniciativa para a realização de uma Gestão de Riscos integrada e contínua. 
6.3 RELAÇÃO ENTRE O MODELO DE ADMINISTRAÇÃO PÚBLICA E AS COMPETÊNCIAS SOCIOEMOCIONAIS

A Gestão de Riscos no IFC utiliza o enfoque baseado na eficiência organizacional para aumentar a chance de atingir os objetivos, por meio de práticas de governança, adotando uma abordagem, predominantemente Mecânica na fase de implantação. Seu objetivo consiste em desenvolver a estrutura e o contexto da Gestão de Riscos de maneira eficiente, confiável e responsável, por meio da elaboração de políticas, formulários e manuais. Já na fase de implementação é adotada uma abordagem Orgânica, com a necessidade de flexibilidade, adaptação e interação, com a finalidade de institucionalizar a Gestão de Riscos.

Este resultado corrobora com o pensamento de Hood e Jackson (1991) apresentado por Secchi (2009), ao considerar que para acontecer uma Reforma da Administração é preciso ter um conjunto de inovações em políticas públicas e de gestão, considerando o alinhamento de valores sobre eficiência, accountability e flexibilidade.

Secchi (2009, p. 365) também considera que "novos modelos organizacionais compartilham algumas características com o modelo burocrático weberiano" por apresentarem uma continuidade da ênfase na função controle, não acontecendo assim uma ruptura. E que "ao invés de falar em ascensão, predomínio e declínio de modelos organizacionais, talvez seja mais frutífero falar em um processo cumulativo de mudanças nas práticas e valores".

Em relação às competências socioemocionais, os traços de comportamentos com maior percepção são justamente aqueles que corroboram com os enfoques do gerencialismo na Nova Administração Pública, porém com grande influência do Novo Serviço Público nos traços de comportamento como: i) confiança, agindo democraticamente; ii) cooperação, contribuindo para a construção do coletivo, com noções compartilhadas; iii) ser prestativo, atuando não só na identificação dos problemas, mas também na busca de soluções; iv) ter consideração pelos colegas, valorizando as pessoas e não somente a produtividade.

\section{CONSIDERAÇÕES FINAIS}

Os desafios sociais, econômicos e educacionais da sociedade do século XXI são intensos e desafiadores e é certo que os conhecimentos cognitivos não são suficientes para uma transformação impactante na sociedade. Torna-se necessário e relevante aprender habilidades sociais e competências socioemocionais para a busca de autoconhecimento, 
autoestima e capacidade de estabelecer relações construtivas.

Todavia, para que a Gestão aconteça, é preciso que haja a institucionalização de um quadro de pessoal competente, envolvendo, assim, um conjunto abrangente de mudanças e transformações.

Os resultados identificaram um considerável equilíbrio da Nova Administração Pública com a teoria do Novo Serviço Público, pois a razão de ser da Gestão de Riscos não está pautada na desconfiança prévia dos administradores públicos por parte da sociedade, mas, sim, na busca pela efetividade orientada pela racionalização organizacional, agregando novos processos de governança e gestão, estruturando desta forma uma liderança compartilhada com o intuito de se gerar um modelo mais cooperativo e flexível.

Para o exercício das atividades como membros do Comitê Local, o fator Conscienciosidade foi apontado como o mais relevante, sendo composto pela confiança, persistência, eficiência e motivação do indivíduo no comportamento em relação ao alcance dos objetivos, alinhando-se, então, à Nova Administração Pública. Entretanto, as características que receberam maior pontuação quanto à importância foram: ser confiável e prestativo, seguido por ser inventivo e cooperativo, sendo possível assim identificar a proximidade com a teoria do Novo Serviço Público.

Portanto, os modelos teóricos possuem em comum o foco na confiança entre os atores, seja para aumentar a eficiência nos controles internos ou para a sistematização do accountability. Importante destacar que tanto na Administração Pública, quanto nas competências socioemocionais, não há nos modelos teóricos qualquer relação de melhor ou pior classificação, uma vez que são modelos abstratos e teóricos que apoiam a observação das principais características de gestão.

Conclui-se que dentre os cinco fatores (Abertura, Conscienciosidade, Extroversão, Amabilidade e Neuroticismo) existe uma predominância de traços de comportamento percebidos por cada servidor, bem como existe um conjunto de competências socioemocionais exigidas para a atividade, as quais os mesmos podem ou não possuir. Nesta toada, percebe-se necessário que o IFC possibilite uma conexão das competências socioemocionais requeridas entre aquelas que o servidor possui, ou que sejam desenvolvidas as consideradas mais relevantes para a função.

Assim, uma vez que o Comitê Local é designado, acredita-se que os servidores precisariam ser capacitados para o exercício da atividade. E de acordo com o presente estudo, 
se faz oportuno tanto o desenvolvimento de competências técnicas, quanto de competências socioemocionais para um efetivo e contínuo Gerenciamento de Riscos.

Como a Gestão de Riscos é uma sequência de atividades que envolvem toda a organização, e sendo o Comitê Local o intermediário de tudo isso, parte-se da premissa que além da capacitação dos atores envolvidos, a organização deveria investir na introdução desta prática na sua cultura, objetivando uma maior compreensão e aceitação por parte dos servidores às mudanças necessárias.

Isso se faz necessário para que todos possam ter uma vida pessoal e profissional mais equilibrada, no qual torna-se necessário lidar com as emoções, além de saber canalizá-las para a adoção de comportamentos e competências socioemocionais compatíveis para a perpetuação de um ambiente de trabalho mais harmônico, positivo e mais produtivo.

\section{REFERÊNCIAS}

ANDION, C. Por uma nova interpretação das mudanças de paradigma na administração pública. Cadernos EBAPE.BR. Rio de Janeiro, RJ, v. 10, n. 1, p. 1-19, mar-2012.

ANDRADE, J. M. de. Evidências de Validade do Inventário dos Cinco Grandes Fatores de Personalidade para o Brasil. Tese (Doutorado em Psicologia Social, do Trabalho e das Organizações) Brasília, DF, 2008.

ÁVILA, Marta Dulcélia Gurgel. GESTÃo DE RISCOS NO SETOR PÚBLICO. Controle estratégico para um processo decisório eficiente. Disponível em:

$<$ https://revistacontrole.tce.ce.gov.br/index.php/RCDA/article/view/110>. Acesso em: 13 dez. 2020.

BISQUERRA A., R.; ESCODA, N. P. Educación Emocional: Estrategias para sai puesta em práctica. Revista de la Asociación de Inspectores de Educación de España, 2012, n.16.

BRASIL. Controladoria Geral da União. Instrução Normativa Conjunta MP/CGU No 01 de 10 de maio de 2016. Disponível em:

$<$ http://www.cgu.gov.br/sobre/legislacao/arquivos/instrucoes_normativas/in_cgu_mpog_01_2 016.pdf $>$. Acesso em: 19 ago. 2020.

CAMPELO, G. S. B.. Administração Pública no Brasil: ciclos entre patrimonialismo, burocracia e gerencialismo, uma simbiose de modelos. Ciência \& Trópico. Recife, PE, v. 34, n. 2, p. 297-323, 2010.

COSO. Committee of Sponsoring Organizations of the Treadway Commission. (2017).

Enterprise risk management: integrating risk with strategy and performance. Jersey City, NJ: Autor. Disponível em: Disponível em: $<$ https://www.coso.org/Documents/2017COSO-ERM-Integrating-with-Strategy-and-Performance-Executive-Summary.pdf $>$. Acesso 
em: 20 mar. 2021.

COUTINHO, Marcelo James Vasconcelos. Administração pública voltada para o cidadão: quadro teórico-conceitual. Revista do Serviço Público, v. 51, n. 3, p. 40-73, 2000.

DELORS, J. et al. Educação um Tesouro a Descobrir: Relatório para a UNESCO da Comissão Internacional sobre Educação para o século XX. UNESCO. Editora: CORTEZ, 1996.

DENHARDT, R. B.; DENHARDT, J. V. The New PublicService :ServingRatherthanSteering. PublicAdministrationReview. BlackwellPublishers Inc. v.60, n.6, p. 549-559, nov/dez-2000.

ENAP. Implementando a Gestão de riscos no setor público. 2018. Disponível em: $<$ https://repositorio.enap.gov.br/bitstream/1/4090/1/Modulo\%203-

Ciclo\%20de\%20Gerenciamento\%20de\%20Riscos.pdf>. Acesso em: 10 fev. 2020.

FADEL, C.; BIALIK, M. TRILLING, B. Educação em Quatro Dimensões: As competências que os estudantes devem ter para atingir o sucesso. Boston, MA: Center for Curriculum Redesign, 2015.

FURLAN, L. de M.; PACHECO, A. S. V.. ANPAD. Gestão de Risco: Estudo de Caso sobre os desafios na Implantação e Implementação. XLIV Encontro da ANPAD - EnANPAD 2020. Disponível em:

$<$ http://www.anpad.org.br/admin/pdf/2020_EnANPAD_ESO1270.pdf $>$ Acesso em: 22 out. 2020.

GOMES, M. L. S.; OLIVEIRA, F. C. de. Modelos Organizacionais de Administração Pública: um estudo dos aspectos da realidade cearense na estrutura de referência das reformas do Estado. Revista de Ciências da Administração. Florianópolis, SC, v. 12, n. 28, p. 105126 , set/dez-2010.

GUIMARÃES, T. de A. A nova administração pública e a abordagem da competência. Revista de Administração Pública - FGV. Disponível em:

$<$ http://bibliotecadigital.fgv.br/ojs/index.php/rap/article/view/6284> Acesso em: 07 nov. 2020 .

HILL, Stephen. Guia sobre a gestão de riscos no serviço público. Brasília. Escola Nacional de Administração Pública - ENAP, 2006. Cadernos ENAP, 30. Disponível em:

$<$ https://repositorio.enap.gov.br/bitstream/1/651/1/Uma\%20explora\%C3\%A7\%C3\%A3o\%20i nicial $\% 20 \mathrm{da} \% 201$ iteratura $\% 20$ sobre $\% 20 \mathrm{a} \% 20$ inova $\% \mathrm{C} 3 \% \mathrm{~A} 7 \% \mathrm{C} 3 \% \mathrm{~A} 3$ o.pdf $>$. Acesso em: 13 dez. 2020.

IFC. Política de Gestão de Riscos. Disponível em: < http://ifc.edu.br/2018/03/23/politica-de gestao-de-riscos/>. Acesso em: 01 fev. 2021. 
MARQUES, A. M.; TANAKA, L. H.; FÓZ, A. Q. B. Avaliação de programas de intervenção para a aprendizagem socioemocional do professor: Uma revisão integrativa. Revista Portuguesa de Educação, 2019. 32(1), pp. 35-51.

MORGAN, G. Imagens da organização. São Paulo: Atlas, 2006.

MORENO, T. C. B.; BORSATTO JUNIOR, J. L.; VESCO, D. G. D.; WALTER, S. A. Capital Intelectual e o Sistema de Controles Gerenciais das Instituições Públicas de Ensino Superior: um Ensaio Teórico sob a Perspectiva da Teoria da Contingência. Revista IberoAmericana de Estratégia, v. 15, n. 3, p. 39-52, 2016.

OLIVEIRA, G. J. Modelos Teóricos da Administração Pública. In: Administração Pública. Campinas, SP: IESDE, 2010

PAES DE PAULA, Ana Paula. Administração Pública brasileira entre o gerencialismo e a gestão social. Revista de Administração Empresarial - RAE. Rio de Janeiro, RJ, v. 45, n.1, p. 36-49, jan/mar-2005.

PALOMERA, R.; BRIONES, E.; GOMEZ-LINARES, A. Formaciónen valores y competências socioemocionales para docentes tras una década de innovación. Prax. Saber, Tunja , v. 10, n. 24, p. 93-117, Dec. 2019.

PICCHIAI, D. Competências Organizacionais, Gerenciais e Individuais: Conceitos e Discussões no Setor Público. Disponível em: <http://www.cc.faccamp.br/ojs-2.4.82/index.php/RMPE/article/view/180> Acesso em: 7 nov. 2020.

RAMOS, A. G. A nova ciência das organizações: uma reconceituação da riqueza das nações. 2. ed. Rio de Janeiro: FGV, 1989.

RICHARDSON, Roberto Jarry. Pesquisa social: métodos e técnicas. São Paulo:Atlas, 1999.

SANTOS, D.; PRIMI, R. Desenvolvimento socioemocional e aprendizado escolar: Uma proposta de mensuração para apoiar políticas públicas. Instituto Ayrton Senna, São Paulo: 2014.

SECCHI. L. Modelos organizacionais e reformas da administração pública. Revista de Administração Pública - RAP. Rio de Janeiro, RJ, v. 43, n. 2, p 347-369, mar/abril-2009.

STEINBERG, R. M. et al. COSO Gerenciamento de Riscos Corporativos - Estrutura Integrada. [S. 1.]: Price water house Coopers LLP, 2007. Disponível em: $<$ https://www.coso.org/Documents/COSO-ERM-Executive-Summary-Portuguese.pdf $>$. Acesso em: 10 out. 2020.

WEBER, Max. Economia e Sociedade: fundamentos da sociologia compreensiva. Brasília, DF : Editora Universidade de Brasília, 1991. 